\title{
Composição centesimal de milho Crioulo coletado em localidades do estado da Paraíba
}

\section{Centesimal composition of corn Crioulo collected in localities of the state of Paraíba, Brazil}

\author{
Dualyson da Silva Santos $^{1 *}$, Shirley Santos Monteiro ${ }^{2}$, Emmanuel Moreira Pereira ${ }^{3}$; Fillipe Silveira Marini ${ }^{4}$; Andreia \\ Vasconcellos ${ }^{5}$; Juliana Ferreira de Lima ${ }^{6}$
}

Resumo: O milho é um dos cereais de maior importância agrícola de largo consumo, na alimentação animal e humana, por ser altamente energético, apresentar excelente composição e inúmeras aplicabilidades. Objetivou-se neste trabalho determinar a composição centesimal de milho crioulo cultivado em diferentes regiões do estado da Paraíba. As determinações analíticas foram conduzidas no laboratório de Análise Físico-química de Alimentos pertencente à Universidade Federal da Paraíba, Campus - III, Bananeiras, Paraíba. As sementes do milho crioulo Jaboatão, foram provenientes dos agricultores familiares de seis municípios situados entre o brejo e o semiárido paraibano. Após a colheita das sementes, foi realizado em Laboratório a seleção e posteriormente a moagem em moinho de faca tipo Willey das amostras para realização das análises. As análises de proteína, lipídeo, cinzas, umidade e carboidratos foram conduzidas no Laboratório de Físico-química de Alimentos para analisar a composição centesimal do milho crioulo Jaboatão. Foi utilizado o delineamento inteiramente casualizado, com oito tratamentos (seis municípios de coleta) e três repetições. Os resultados obtidos para as análises de proteína e cinzas em milho crioulo Jaboatão apresentaram maiores teores em amostras obtidas do município de Alagoa Nova, onde apresentaram com menor percentual de umidade no material avaliado. Para lipídeos obteve-se maior teor o milho obtido do município de Massaranduba 1, sendo que, as amostras oriundas do município de Remígio 2 tiveram melhor percentual de carboidrato quando comparado com os demais municípios analisados. A variedade de milho crioulo Jaboatão cultivada por agricultores familiares tem potencial nutricional para ser utilizado como fonte de alimentação.

Palavras-chave: Agricultura familiar; Sementes da paixão; Qualidade nutricional.

\begin{abstract}
Corn is one of the cereals of major agricultural importance of consumption, animal and human, being highly energetic, presenting excellent composition and numerous applicabilities. The objective of this work was to determine the centesimal composition of criollo corn cultivated in different regions of the State of Paraíba. The analytical determinations were conducted in the Laboratory of Physical-Chemical Analysis of Food belonging to the Federal University of Paraíba, Campus - III, Bananeiras, Paraiba. The seeds of the Jaboatão Creole maize came from the family farmers of six municipalities located between the swamp and the semi-arid Paraiba. After the seeds were harvested, the selection and subsequent milling of the Willey-type knife of the samples were performed in the laboratory for the analysis. The analyzes of protein, lipid, ashes, moisture and carbohydrates were conducted at the Physical Chemistry Laboratory of Foods to analyze the centesimal composition of the Jaboatão Creole maize. A completely randomized design was used, with eight treatments (six collection municipalities) and three replications. The results obtained for the protein and ash analyzes in Jaboatão Creole maize had higher levels in samples obtained from the city of Alagoa Nova, where they presented with lower percentage of moisture in the evaluated material. For lipids the maize obtained from the municipality of Massaranduba 1 was higher, and the samples from the municipality of Remígio 2 had a better percentage of carbohydrate when compared to the other municipalities analyzed. The Jaboatão maize variety cultivated by family farmers has nutritional potential to be used as a food source.
\end{abstract}

Key words: Family farming; Seeds of passion; Nutritional quality.

\footnotetext{
*Autor para correspondência

Recebido para publicação em 04/02/2018; aprovado em 12/06/2018

${ }^{1}$ Bacharel em Agroecologia, Universidade Federal da Paraíba. Centros de Ciências Humanas, Sociais e Agrárias, Bananeiras Paraíba, dualyson@ hotmail.com ${ }^{2}$ Pós-Graduação em Tecnologia Agroalimentar, Universidade Federal da Paraíba. Centros de Ciências Humanas, Sociais e Agrárias, Bananeiras, Paraíba shirley_pinto_monteiro@hotmail.com

${ }^{3}$ Doutorando em Agronomia, Universidade Estadual Paulista, Faculdade de Ciências Agrárias e Veterinárias, Jaboticabal, emmanuel16mop@ hotmail.com

${ }^{4}$ Docente/Pesquisador do Departamento de Geociências, Universidade Federal da Paraíba, João Pessoa, fsmarini@yahoo.com.br

${ }^{5}$ Doutorando em Extensão Rural, Universidade Federal de Santa Maria, Santa Maria, dreagroeco@gmail.com

${ }^{6}$ Pós-Graduação em Ciências Agrárias (Agroecologia), Universidade Federal da Paraíba. Centros de Ciências Humanas, Sociais e Agrárias, Bananeiras, Paraíba. julianacavnufpb@hotmail.com.
} 


\section{INTRODUÇÃO}

O milho (Zea mays) pertence à Poaceae, é originaria do México. O Brasil ganha destaque como sendo um dos maiores produtores mundial deste cereal, com uma produção que se aproxima de 89,2 milhões de toneladas em 2017/18 e com uma expectativa para 113,2 milhões de toneladas para 2027/28. Apresentando ainda, uma demanda interna é de $66,7 \%$ da produção (BRASIL, 2017). O milho é o segundo grão mais produzido no país, perdendo somente para a soja, chegando a aproximadamente 78,69 milhões de toneladas em 2015 (CONAB, 2015).

Considera-se o milho como uma das culturas mais importantes mundial, por ser constituinte de matéria-prima básica para uma ampla gama de aplicações, tais como: produção de amido, óleo, farinha, glicose e outros, entretanto, a sua maior utilização é na produção de rações, principalmente para as atividades de avicultura e suinocultura (FIALHO; BARBOSA, 2005).

Segundo Guimarães e Barros (2006), a cultura do milho é cultivada na maioria das propriedades rurais do país, sendo dividida em duas realidades de produção: em pequenas propriedades, onde o nível tecnológico aplicado é baixo e a reutilização de sementes de um ano para o outro, geralmente sem adubação e consorciado com outra cultura; a outra realidade são propriedades com níveis de tecnologias avançadas e que vem aumentado juntamente com o uso de híbridos melhorados e de grande produtividade.

Em termos de fonte proteica este cereal deixa a desejar, pois além de possuir baixos teores de proteína (cerca de $10 \%$ ), essa é de baixa qualidade biológica, principalmente em relação aos aminoácidos essenciais. Pequenas variações nos conteúdos proteicos têm sido observadas em amostras de grãos de milho, em função da fertilidade do solo, condições climáticas e sistemas de manejo (OLIVEIRA et al., 2004).

De acordo com Cereda et al. (2002), o amido de milho nativo, com umidade na faixa de $10-12 \%$, apresenta cerca de $0,7 \%$ de lipídios. As primeiras variedades do milho ricas em óleos foram desenvolvidas em 1986 e híbridos contendo lipídeos entre 6-8\% estão disponíveis no mercado. Segundo Hojilla-Evangelista e Johnson, (2003), o uso destas variedades ricas em lipídeos reside majoritariamente na alimentação animal, devido a sua alta energia metabolizável na alimentação.

$\mathrm{O}$ teor de umidade em sementes, se resume na quantidade relativa de água presente no grão. Diversas operações de pós-colheita realizadas no produto para manter a qualidade durante o armazenamento (SILVA et al., 2008).

No entanto, segundo Catão et al. (2010), as sementes de variedades locais possuem valor inestimável para as populações tradicionais, por serem consideradas componentes da agrobiodiversidade. A lei de sementes de n. 10.711/03, que entrou em vigor no Brasil em agosto de 2003, estabelece o sistema nacional de sementes e mudas, com objetivo de garantir a identidade e a qualidade do material de multiplicação e de reprodução vegetal produzido, comercializado e utilizado no país. Legislação, na qual, as sementes crioulas passam a ser oficialmente reconhecidas. Contudo, a lei não regulamenta o controle de qualidade do material crioulo, ao contrário das cultivares comerciais existentes no mercado de sementes (CAMPOS et al., 2006).
Pouco sabe-se a respeito da qualidade química das sementes crioulas produzidas no estado da Paraíba, ainda mais nas diferentes regiões.

Diante do exposto, o objetivo do presente estudo foi determinar a composição centesimal da variedade de milho crioulo cultivado em diferentes regiões do estado da Paraíba.

\section{MATERIAL E MÉTODOS}

O experimento foi conduzido no Laboratório de Tecnologia de Sementes em parceria com o Laboratório de Físico-química de Alimentos ambos pertencentes ao Centro de Ciências Humanas, Sociais e Agrárias (CCHSA) da Universidade Federal da Paraíba (UFPB), Campus - III Bananeiras - PB. As sementes do milho crioulo Jaboatão, provenientes da agricultura familiares de seis municípios (Casserengue, Remígio, Massaranduba, Montadas, Alagoa Nova e Matinhas) situados entre o brejo e o semiárido paraibano.

Após a colheita dos grãos, foram conduzidos ao laboratório, seguindo a etapa de seleção para proceder as avaliações. Os grãos foram moídos em moinho de faca tipo Willey, obtendo aproximadamente $100 \mathrm{~g}$ para condução das análises.

As avaliações foram realizadas no Laboratório de Físico-química de Alimentos. Para a caracterização da composição centesimal do milho crioulo Jaboatão foram analisados os seguintes parâmetros: proteínas, lipídeos, cinzas, umidade e carboidratos.

Para determinação de proteínas utilizou-se o método de micro Kjeldahl, utilizando $1 \mathrm{~g}$ de amostra. O procedimento baseou-se na digestão da amostra com uma solução catalítica e ácido sulfúrico concentrado as amostras foram digeridas em bloco digestor a $\pm 450{ }^{\circ} \mathrm{C}$ até completa a oxidação do carbono, em seguida a amostra foi resfriada em temperatura ambiente, destilando-se a amostra digerida em meio básico por adição de Fenolftaleína, acoplado o tubo no destilado nitrogênio onde foi feita a neutralização da amostra com uma solução saturada de hidróxido de sódio após a destilação foi recolhida aproximadamente $125 \mathrm{ml}$ da solução destilada (Equação 1) (IAL, 2008).

$\left(\%\right.$ de Proteína $\left.=\frac{\text { Vg.Fc Hcl x FcC x 0,14 }}{\mathrm{Pa}}\right)$

Em que: $\mathrm{Vg}=$ volume gasto na bureta, $\mathrm{FcHc1}=$ fator de correção do $\mathrm{Hc} 1, \mathrm{FcC}$ = fator de conversão do $\mathrm{N}$ em proteínas de acordo com o tipo de alimentos.

Determinação do teor de lipídeos, utilizou-se o método de Folch, que se baseia na extração de gordura a frio utilizando uma mistura de dois solventes de clorofórmio/metanol (2:1), sulfato de sódio a 1,5\%, formando uma solução homogênea para a determinação de lipídeos utilizando $2 \mathrm{~g}$ de cada amostra sendo colocado em um a proveta e adicionando-se sulfato de sódio a 1,5\% as provetas foram tampadas e agitadas por $1 \mathrm{~min}$. em seguida foi deixado em repouso com proveta tampada até que se houve a separação de fases, coletou-se o sobrenadante, sendo filtrado com papel filtro e adicionado $10 \mathrm{ml}$ de sulfato de sódio (P.A), retirando dessa amostra $5 \mathrm{ml}$ e transferido para uma cápsula de alumínio e colocado para secar em estufa a $105{ }^{\circ} \mathrm{C}$ por uma hora e resfriada em temperatura ambiente, com o auxílio de um dissecador (Equação 1) (IAL, 2008). 


$$
\left(\% \text { de Lipídios }=\frac{(\text { PcL }- \text { Pc }) \times \text { Vif } \times 100}{P a \times 5}\right)
$$

Em que: $\mathrm{Pcl}=$ Peso da cápsula com lipídeos, $\mathrm{Pc}=$ Peso da cápsula vazia, Vif $=$ Volume inferior medido na proveta, $\mathrm{Pa}=$ Peso da amostra.

Para a quantificação de cinzas utilizou-se o método de forno Mufla a $550{ }^{\circ} \mathrm{C}$, primeiramente os cadinhos de porcelana foram secos em estufa a $105^{\circ} \mathrm{C}$ por uma hora e em seguida mantidos no dessecado até atingirem temperatura ambiente. Em seguida foram pesadas em torno de cinco gramas de amostra em cada cadinho de porcelana, as mesmas foram carbonizadas na mufla por $6 \mathrm{~h}$ e após esse período foram retiradas e postas no dessecado até atingirem temperatura ambiente e pesadas para determina o teor de cinzas (Equação 1) (IAL, 2008).

$$
\% \text { de Cinzas }=\frac{\operatorname{Pcc}-\mathrm{Pc} \times 100}{\mathrm{~Pa}}
$$

Em que: Pc $=$ Peso do cadinho, Pcc $=$ Peso do cadinho mais cinza, $\mathrm{Pa}=$ Peso da amostra.

Para o teor de umidade utilizou-se o método de estufa a $105^{\circ} \mathrm{C}$, as amostras foram pesadas em uma balança analítica, com cápsulas de porcelana previamente seca em estufa a 105 ${ }^{\circ} \mathrm{C}$ durante $1 \mathrm{~h}$ e esfriada em dissecador por $30 \mathrm{~min}$., foi pesado em torno de $5 \mathrm{~g}$ da amostra em cada cápsula, em seguida foram levadas para a estufa a $105{ }^{\circ} \mathrm{C}$ durante $24 \mathrm{~h}$, posteriormente as amostras foram postas em dessecador para atingir temperatura ambiente e pesada em uma balança analítica, sendo determinado o teor de umidade final (Equação 4) (IAL, 2008).

$$
\% \text { Umidade }=\frac{\mathrm{Pa}-(\mathrm{Pcas}-\mathrm{Pc}) \times 100}{\mathrm{~Pa}}
$$

Em que: Pc $=$ Peso da cápsula, $\mathrm{Pa}=$ Peso da amostra, Pcas $=$ Peso da cápsula com amostra seca.

A determinação do percentual de carboidrato se deu através da subtração dos resultados dos teores de lipídeos, proteínas, umidade e cinzas de cem (Equação 5) (IAL, 2008).

$$
\% \text { Carboidrato }=(100-\mathrm{P}-\mathrm{L}-\mathrm{C}-\mathrm{U})
$$

Em que: $\mathrm{P}=$ proteína, $\mathrm{L}=$ Lipídeos, $\mathrm{C}=$ Cinzas, $\mathrm{U}=$ Umidade.

A avaliação entre os tratamentos foi realizada através da análise de variância (ANOVA). Os resultados foram comparados pelo teste de $\mathrm{F}$ a $5 \%$ de significância entre os tratamentos. Os resultados estatísticos foram tratados pelo software ASSISTAT na versão 7.7 (SILVA; AZEVEDO, 2016).

\section{RESULTADOS E DISCUSSÃO}

Observou-se efeito significativo $(\mathrm{P}>0,05)$ para os teores de proteínas nas diferentes regiões avaliadas. Os menores percentuais foram evidenciados na região de Casserengue, com valores em torno de 7\%. Os maiores percentuais proteicos foram evidenciados na região de Alagoa Nova, chegando a valores superiores a 14\%, (Figura 1). Contudo os valores proteicos encontrados nesse trabalho, em todas as áreas avaliadas estão dentro dos percentuais encontrados por outros autores para a qualidade proteica de milho, variando de 7,77 a 15,8\% (EIZENDEHER et al., 2005; JIAN et al., 2007; SCHUH et al., 2011, MAHESH et al., 2013; CAZARESSÁNCHEZ, et al., 2015). Essa variação pode ser atribuída as condições ambientais de cada região, além do manejo cultural empregado por cada produtor.

Figura 1. Teores de proteínas em milho Crioulo Jaboatão, em diferentes regiões de produção.

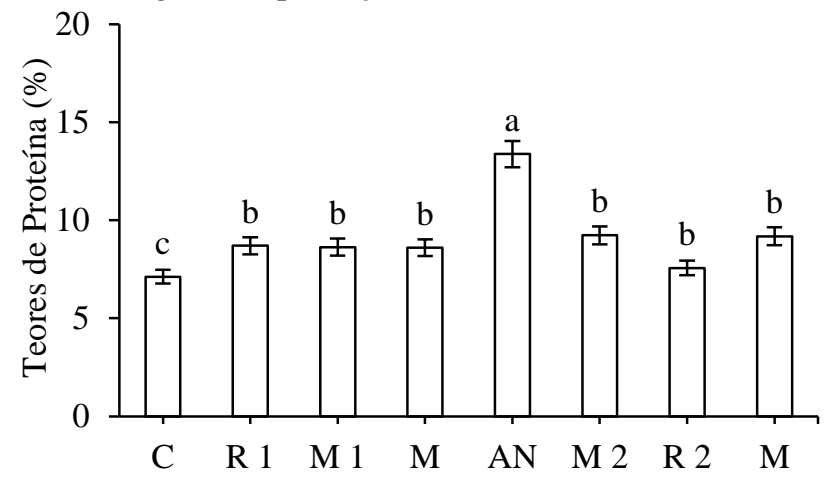

C - Casserengue; R1 - Remígio 1; M1 - Massaranduba 1; M - Montadas; AN - Alagoa Nova; M2 - Massaranduba 2; R2 - Remígio 2; M - Matinhas.

Observou-se efeito significativo $(\mathrm{P}>0,05)$ para o teor de lipídeos nas diferentes regiões avaliadas. Os teores de lipídeos variaram de acordo com a região de produção, variando de 2,2 a $5 \%$ (Figura 2), os menores percentuais foram encontrados na região de Alagoa Nova e Remígio chegando a um valor médio de 2,5\%, os maiores percentuais foram observados nas regiões de Massaranduba e Montadas, com 5 e $4,7 \%$, respectivamente (Figura 2).

De acordo com Paes (2011), o percentual de lipídios presentes na semente de milho em média é de $4,5 \%$. Os baixos teores de lipídeos encontrados nas regiões de Casserengue; Remígio 1; Alagoa Nova; Massaranduba 2; Remígio 2; Matinhas, pode ser atribuído a oxidação lipídica a época de produção e a fatores ambientais como a temperatura.

Figura 2. Teor de lipídeos em milho Crioulo Jaboatão, em diferentes regiões de produção.

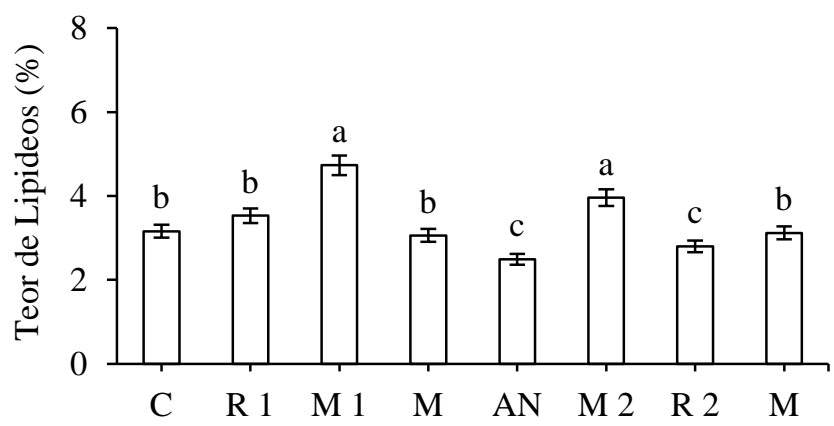

C - Casserengue; R1 - Remígio 1; M1 - Massaranduba 1; M - Montadas; AN - Alagoa Nova; M2 - Massaranduba 2; R2 - Remígio 2; M - Matinhas.

Observou-se efeito significativo $(\mathrm{P}>0,05)$ para os teores de cinzas nas diferentes regiões avaliadas. Os teores de cinzas, variando de 0,45 e $0,06 \%$, as regiões que apresentaram os menores desempenhos foram observadas nos municípios de Massaranduba 1 com 0,06\%, seguido de Remígio 1 com $0,06 \%$, os maiores percentuais foram os municípios de Alagoa Nova com $0,45 \%$ seguido de Massaranduba 2 com 0,23\% (Figura 3). 
Figura 3. Teor de cinzas em milho Crioulo Jaboatão, em diferentes regiões de produção.

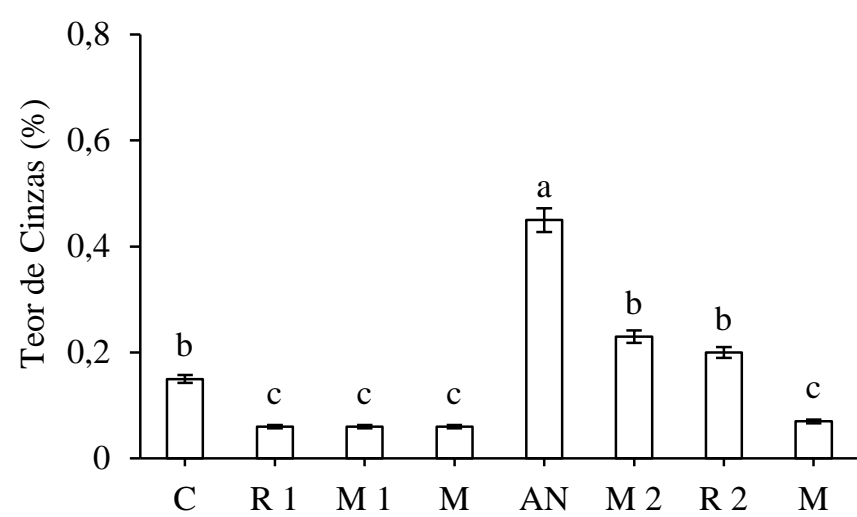

C - Casserengue; R1 - Remígio 1; M1 - Massaranduba 1; M - Montadas; AN - Alagoa Nova; M2 - Massaranduba 2; R2 - Remígio 2; M - Matinhas.

Os resultados obtidos neste estudo, foram inferiores aos encontrados na literatura, com valores médios de 1,38 (SCHUH et al., 2011). Essa discrepância encontrada pode ser atribuída ao fator da nutrição do solo, onde o material carbonizado ao final do processo de obtenção de cinzas são os minerais presentes, devendo-se também ser levado em consideração o tipo de manejo utilizado na produção da cultura, como as capinas feitas, onde vão influenciar na nutrição e competição com plantas espontâneas.

Observou-se efeito significativo $(\mathrm{P}>0,05)$ para os teores de umidade nas diferentes regiões avaliadas. Os variando de 13,75 e $11,53 \%$ (Figura 4), os menores percentuais foram observados nas regiões de Matinhas e Alagoa Nova, com 11,93 e $11,53 \%$, respectivamente, os maiores valores foram observados nas regiões de Casserengue, Remígio $1 \mathrm{e}$ Massaranduba 2, com um valor médio de 14\% (Figura 4).

Figura 4. Teor de umidade em milho Crioulo Jaboatão, em diferentes regiões de produção.

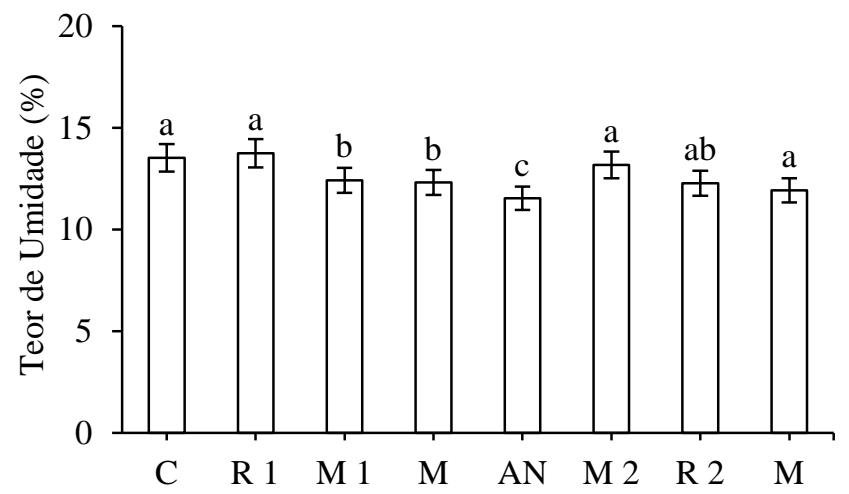

C - Casserengue; R1 - Remígio 1; M1 - Massaranduba 1; M - Montadas; AN - Alagoa Nova; M2 - Massaranduba 2; R2 - Remígio 2; M - Matinhas.

Os valores encontrados neste estudo para o ter umidade em milho são superiores aos da literatura, com valores médios de 13\% (PINTO et al., 2009; PERES; JANDISLAU, 2011; SARMENTO et al., 2015).

A presença de água nos produtos químicos ou biológicos ocorre como atividade de água e água ligada, resultando em conteúdo total de água (teor de umidade). Altos percentuais de umidade não são desejados para grãos, principalmente armazenados, uma vez que a água acelera os processos bioquímicos de deterioração e ou germinação (EIZENDEHER et al., 2005).

Não foram observados efeito significativo $(\mathrm{P}>0,05)$ para os teores de carboidratos nas diferentes regiões avaliadas. As regiões apresentaram um valor médio de $75 \%$ para teor de carboidrato em milho (Figura 5).

Figura 5. Teor de carboidrato em milho Crioulo Jaboatão, em diferentes regiões de produção.

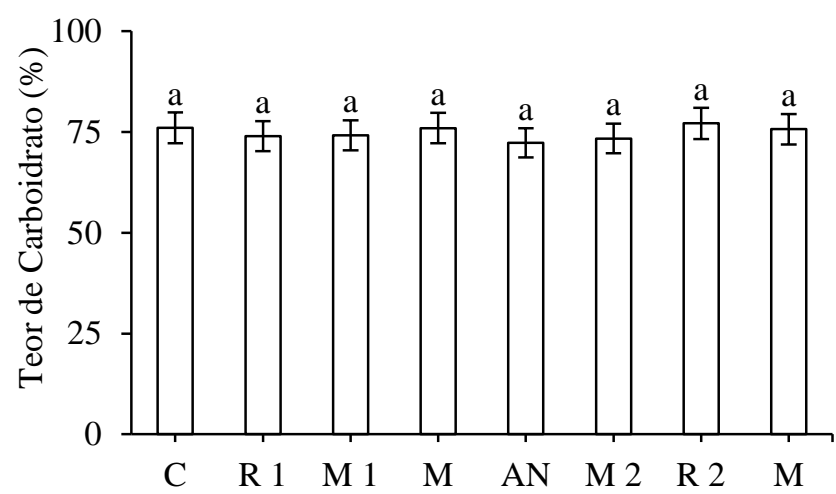

C - Casserengue; R1 - Remígio 1; M1 - Massaranduba 1; M - Montadas; AN - Alagoa Nova; M2 - Massaranduba 2; R2 - Remígio 2; M - Matinhas.

Os resultados encontrados são superiores os encontrados na literatura, conforme em estudos realizados por Giacomelli et al. (2012) que encontraram $71,49 \%$ de carboidratos para farinha de milho pré-cozida. Kokuszka e Murate (2007) encontrou teores de carboidratos de $74,46 \%$ para milho em sistemas de cultivo convencional e teores de $71,67 \%$ para sistema de cultivo Agroecológico. Os elevados percentuais de carboidratos encontrados poder ser atribuídos a fator genético do milho crioulo Jaboatão, além das características edafoclimáticas das regiões de cultivo.

\section{CONCLUSÕES}

A variedade de milho crioulo Jaboatão cultivada por agricultores familiares tem potencial nutricional para ser utilizada como fonte de alimentação.

O milho Jaboatão de Alagoa Nova possui um percentual de proteínas alto e o milho de Massaranduba 1 tem o alto teor de lipídeos.

\section{REFERÊNCIAS}

BRASIL. Ministério da Agricultura, Pecuária e Abastecimento. Projeções do Agronegócio: Brasil 2016/2017 a 2026/2027. Ministério da Agricultura, Pecuária e Abastecimento. Assessoria de Gestão Estratégica. - Brasília: Mapa/ACS, 2017.

CATÃO, H. C. R. M.; COSTA, F. M.; VALADARES, S. V.; DOURADO, E. da R.; BRANDÃO JÚNIOR, D. da S.; SALES, N. de L. P. Qualidade física, fisiológica e sanitária de sementes de milho crioulo produzidas no norte de Minas Gerais. Ciência Rural, v. 40, n. 10, p. 2060-2066, 2010.

CAMPOS, S. R. F.; MOURA, W. de M.; PERTEL, J.; LIMA, P. C. de. Aspectos legais da produção e da comercialização de sementes. Informe Agropecuário, Belo Horizonte, v. 27, n. 232, p. 15-21, 2006. 
CAZARES-SÁNCHEZ， E.; CHÁVEZ-SERVIA， J. L.; SALINAS-MORENO, Y.; CASTILLO-GONZÁLEZ, F.; RAMIREZ-VALLEJO, P. Variação da composição de grãos entre milho nativo (Zea mays L.) de Yucatan, México. Agrociencia, v. 49, n. 1. p. 15-30, 2015.

CEREDA, M. P., FRANCO, C. M. L., DAIUTO, E. R., DEMIATE, I. M., CARVALHO, L. J. C. B., LEONEL, M., VILPOUX, O. F., SARMENTO, S. B. S. Propriedades gerais do amido - culturas de tuberosas amiláceas latino-americanas. v.1, Ed. Fundação Cargill, São Paulo. Brasil, 2002.

CONAB. Companhia Nacional do Abastecimento série histórica. Comparativo de área, produção e produtividade. $2015 . \quad$ Disponível em: http://www.conab.gov.br/conabweb/index. Acesso em: 23/08/2017.

EIZENDEHER, L. B.; FREITAS, R. J. S.; CANÇADO, R. A. Incidência de aflatoxinas B1, B2, G1 e G2 em doces de amendoim e amendoim in natura comercializados no Estado do Paraná. Higiene Alimentar, São Paulo, v. 19, n. 129, p. 101-104, 2005.

FIALHO, E. T., BARBOSA, H. P. Alimentos Alternativos para Suínos. Lavras - MG, FAEPE, 175 p., 2005.

GUIMARÃES, V. D. A.; BARROS, G. S. A. C. Análise do armazenamento de milho no Brasil em um mercado de economia aberta. Revista de Economia e Sociologia Rural, Rio de Janeiro, v. 44, n. 04, p. 751-771, 2006.

GIACOMELLI, D.; MONEGO, B.; DELAGUSTIN, M. G.; BORBA, M. M.; RICALDE, S. R.; FACCO, E. M. P.; SIVIERO, J. Composição nutricional das farinhas de milho e da polenta. Alimentos e Nutrição, Araraquara, v. 23, n. 3, p. 415-420, 2012.

HOJILlA-EVANGELISTA, M. P.; JOHNSON, L. A. Sequential extraction processing of high-oil corn. Cereal Chemistry, v. 80, p. 679-683, 2003.

IAL. Instituto Adolfo Lutz. Normas Analíticas do Instituto Adolf Lutz: Métodos Químicos e Físicos para Analises de alimentos. $4^{\text {a }}$ ed., Digital, São Paulo, 1020 p., 2008.

JIANG, H. Y.; ZHU, Y. J.; WEL, L. M.; DAÍ, J. R.; SONG, T. M.; YAN, Y. L. CHEN, S. J. Analysis of protein, Starch and oil contend of single intact by near infrared reflectance Spectroscopy (NIRS) in maize (Zea mays L.). Plant Breending, v. 126, n. 5, p. 492-497, 2007.

KOKUSZKA, R.; MURATE, E. H. Valor nutricional de milho produzido em sistemas de produção convencional e agroecológico. Revista Brasileira de Agroecologia, v. 2, p. 566-569, 2007

MAHESH, N.; WALI, M. C.; GOWDA, M. V. C.; MOTAGI, B. N. E UPPINAL, N. F. Genetic analysis of grain yield, starch, protein and oil content in single cross hybrids of maize. Karnataka Journal of Agricultural Sciences, v. 26, p. 185-189, 2013.

OLIVEIRA, J. P.; CHAVES, L. J.; DUARTE, J. B.; BRASIL, E. D.; JUNIOR, L. T. F.; RIBEIRO, K. O. Teor de proteína no grão em populações de milho de alta qualidade proteica e seus cruzamentos. Pesquisa Agropecuária Tropical, v. 34, p. 45-51 2004.

PAES, M. C. D. Milho: a evolução do seu consumo na dieta humana através dos povos e do tempo. Sete Lagoas: EMBRAPA, 2011 (Jornal Eletrônico da Embrapa Milho e Sorgo). Disponível em: https://ainfo.cnptia.embrapa.br/digital/bitstream/item/39582/1 /Milho-evolucao.pdf. Acesso em: 09/08/2017.

PERES, W. L. R.; JANDISLAU, J. L. Testes de vigor em sementes de milho. In: XVII Congresso Brasileiro de Sementes, 2011, Natal RN. Informativo Abrates. Belo Horizonte, v. 21, p. 3-200, 2011.

PINTO, A. T. B.; PEREIRA, J.; OLIVEIRA, T. R.; PRESTES, R. A.; MATTIELO, R. R.; DEMIATE, I. M. Characterization of corn landraces planted grown in the campos gerais region (Paraná, Brazil) for industrial utilization. Brazilian Archives of Biology and Technology, v. 52, p. 17-28, 2009.

SARMENTO, H. G; DAVID, A, M. S. S; BARBOSA, M. G. Determinação do Teor de Água em Sementes de Milho, Feijão e Pinhão -Manso por Métodos Alternativos. Energia na Agricultura, Botucatu SP, v. 30, n. 3, p. 249-256, 2015.

SCHUH, G.; GOTTARDI, R.; FERRARI FILHO, E.; GUIMARÃES ANTUNES, L. E.; GOMES DIONELLO, R. Efeitos de dois métodos de secagem sobre a qualidade físicoquímica de grãos de milho safrinha-RS, armazenados por 6 meses. Semina: Ciências Agrárias, n. 32, v. 1, p. 235-244, 2011.

SILVA, J. S. Secagem e Armazenagem de Produtos Agrícolas. 2 ${ }^{a}$ Edição. Viçosa: Aprenda Fácil, 2008. p. 560.

SILVA, F. de A. S.; AZEVEDO, C. A. V. de. The Assistat Software Version 7.7 and its use in the analysis of experimental data. African Journal of. Agricultural Research, v. 11, n. 39 , p. 3733-3740, 2016. 10.5897/AJAR2016.11522 